\title{
Molecular Modeling, Geometry Optimization and Characterization of Bimetallic Complexes Derived from s-Indacene
}

\author{
Pushpavathi Itte, M.K. Amshumali*, Mussavir Pasha, K.M \\ Department of Chemistry/Industrial Chemistry, Vijayanagara Sri Krishnadevaraya University, Jnanasagara Campus, India
}

Copyright $(2017$ by authors, all rights reserved. Authors agree that this article remains permanently open access under the terms of the Creative Commons Attribution License 4.0 International License

\begin{abstract}
The molecular modeling, geometry optimization and characterization of bimetallic complexes derived from 4, 8-dimethyl-2, 6-diphenyl-1, 5-dihydro-s-indacene has been performed using semi empirical method. The three bimetallic complexes containing transition metals $\mathrm{Fe}, \mathrm{Ni}$ and $\mathrm{Fe}-\mathrm{Ni}$ were investigated. Namely, $\left(\mathrm{Cp}^{*} \mathrm{Fe}\right)_{2} \mathrm{Ic}^{\prime}, \quad(\mathrm{Cp} * \mathrm{Ni})_{2} \mathrm{Ic}$, (Cp*Fe)Ic'(Cp*Ni). (Where

$\mathrm{Cp}^{*}=$ Pentamethyl- $\eta^{5}$-cyclopentadienyl, Ic' $=2,6$ diphenyl-4, 8-dimethyl-s- Indacene.) In these study geometrical parameters, vibrational frequencies, dipole moment and total energies were calculated by PM6, parametric method. The theoretical electronic (UV-Vis) spectrum calculated using TD-SCF (RPM6) in gas phase. The frontier orbital analyses measure the values of HOMO, LUMO energies and their energy gap. The calculated HOMO-LUMO energy gap show that charge transfer occurs within the molecule.
\end{abstract}

Keywords Organobimetallic Complexes, Semi Empirical, PM6, Optimization, Energy Gap, Vibrational Frequency, Indacene

\section{Introduction}

Organometallic transition bimetallic complexes are of great interest, not only due to their fascinating structural and bonding variations but also due to their potential applicability as catalytic and stoichiometric reagents. S-Indacene ligand is capable of bridging two or more metal centers using organometallic bonds, especially with fused aromatics [1], have shown considerable interest owing to their ability to couple the redox activity of various metal centers. These ligands may connect two or more organometallic centers, which may have different oxidation states and allow interaction between them. This paper includes the theoretical study of homobinuclear complexes of transition metals such as $\mathrm{Fe}$ and $\mathrm{Ni}$.Also, heterobinuclear complexes with combinations of metals such as, Fe-Ni. In this paper, We have undertaken a detailed study of Structural and spectroscopic analysis of these bimetallic complexes derived from partially methylated s-indacene [2]-[8], here in we report the band gap, electrostatic potential and spectroscopic properties of the above stated bimetallic complexes.

\section{Computational Details}

All computations were carried out using semi empirical methods with Gaussian '09 program package. Semi-empirical methods follow what are often called empirical methods where the two-electron part of the Hamiltonian is not explicitly included. For $\pi$-electron systems, this was the Huckel method proposed by Erich Huckel $^{[12]-[14]}$. For all valence electron systems, the extended Huckel method was proposed by Roald Hoffmann ${ }^{[15]}$.MOPAC and Chem 3D ultra-program was used for a visual presentation. The geometry of homo bimetallic complexes of $\mathrm{Fe}, \mathrm{Ni}$ and heterobimetallics (Fe-Ni metals) were optimized using semi empirical quantum chemical computation [16]-[19] with PM6 parametric method using Gaussian'09 program. In this present computational scheme vibrational analysis of molecules were also performed at the same level of theory. Optimized geometrical parameters such as bond lengths and bond angles and dihedral angles and frequencies calculated for three complexes shown in fig $1 \mathrm{a}$, $1 \mathrm{~b}$ and $1 \mathrm{c}$.respectively.

$\mathrm{Fe}$ is bonded in a $\eta^{5}$-coordination with two ligands $\left(\mathrm{Cp}^{*}\right.$ and Ic') on both sides. Where $\mathrm{Cp}^{*}=$ Pentamethyl- $\eta^{5}$-Cyclopentadienyl, $\quad \mathrm{Ic}^{\prime}=2,6$ Diphenyl-4, 8-dimethyl-s-Indacene. 


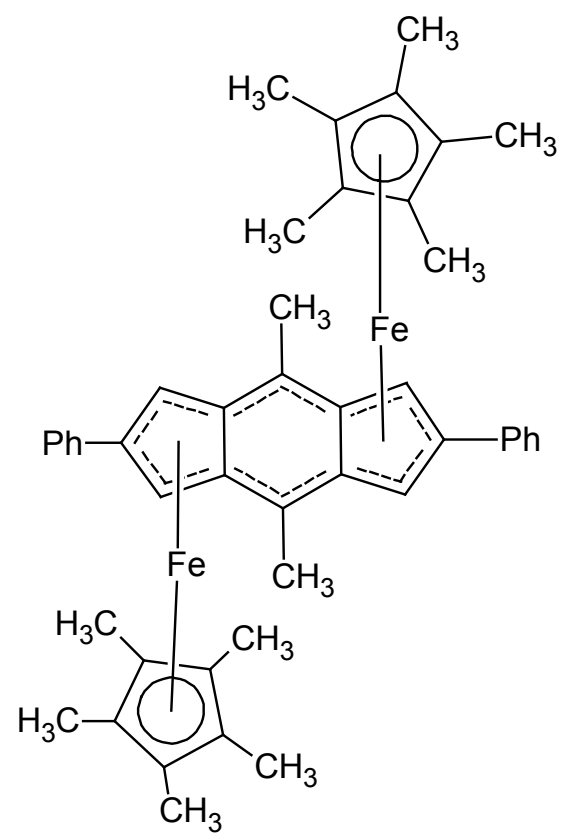

Figure 1a. Chemical structure of $\left(\mathrm{Cp}^{*} \mathrm{Fe}\right)_{2} \mathrm{Ic} \mathrm{c}^{\prime}$<smiles></smiles>

Figure 1b. Chemical structure of $\left(\mathrm{Cp}^{*} \mathrm{Ni}\right)_{2} \mathrm{Ic}$ '
$\mathrm{Ni}$ is bonded in a $\eta^{5}$-coordination with two ligands $\left(\mathrm{Cp}^{*}\right.$ and Ic') on both sides. Where $\mathrm{Cp} \mathrm{p}^{*}=$ Pentamethyl $-\eta^{5}$-Cyclopentadienyl, $\quad$ Ic' $=2,6$ Diphenyl-4, 8-dimethyl-s-Indacene<smiles></smiles>

Figure 1c. Chemical structure of $\left(\mathrm{Cp}^{*} \mathrm{Fe}\right) \mathrm{Ic} \mathrm{c}^{\prime}(\mathrm{Cp} * \mathrm{Ni})$

$\mathrm{Fe}, \mathrm{Ni}$ are bonded in a $\eta^{5}$-coordination with two ligands $\left(\mathrm{Cp}^{*}\right.$ and Ic') on both sides. Where $\mathrm{Cp}^{*}=$ Pentamethyl $-\eta^{5}$-Cyclopentadienyl, $\quad \mathrm{Ic}^{\prime}=2$, 6Diphenyl-4, 8-dimethyl-s-Indacene.

\section{Results and Discussion}

\subsection{Molecular Geometry Optimization}

Geometry optimization was carried out to find out the best atomic arrangement that makes the molecule more stable. Optimized geometrical parameters such as bond lengths and bond angles and dihedral angles of Iron bimetallic complex calculated by semi empirical methods using parameter PM6[21]-[23].The optimized structures with atom labeling and number labeling of Iron bimetallic complex are shown in Fig. 2. 


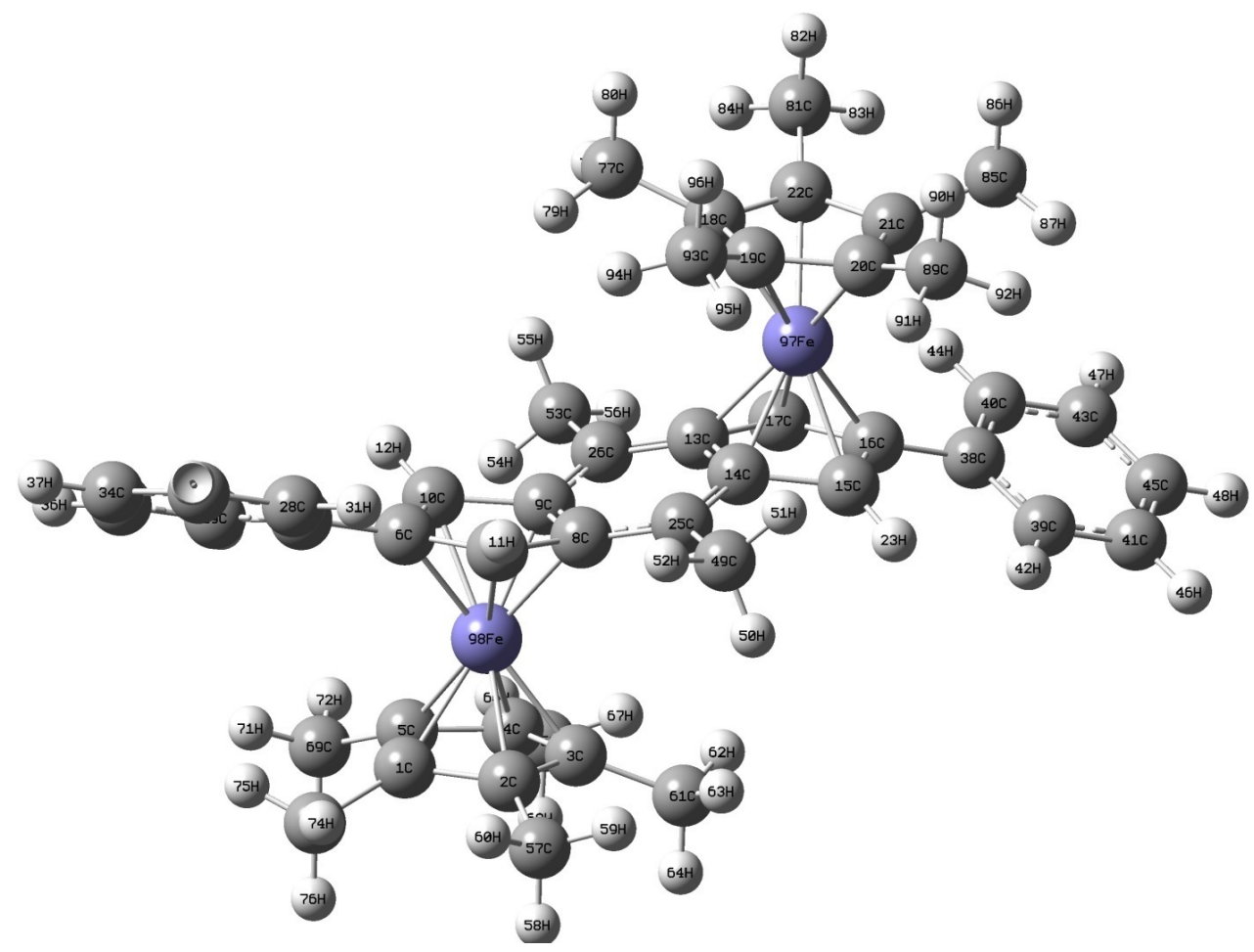

Figure 2. Atom and number labeling of Optimized structure of $\left(\mathrm{Cp}^{*} \mathrm{Fe}\right)_{2} \mathrm{Ic}^{\prime}$

Table 1. Optimized bond lengths between Metal, Indacene and Cyclopentadienyl ligands in various bimetallic complexes

\begin{tabular}{|c|c|c|c|}
\hline Bond Length & Fe com & Ni com & Fe-Ni com \\
\hline $\mathrm{Cp} \mathrm{C}_{18}-\mathrm{M}_{97}$ & 2.018 & 2.023 & 2.030 \\
\hline (Indacene) $\mathrm{C}_{17}-\mathrm{M}_{97}$ & 1.984 & 1.995 & 1.983 \\
\hline (Indacene) $\mathrm{C}_{10}-\mathrm{M}_{98}$ & 1.982 & 1.994 & 2.018 \\
\hline $\mathrm{Cp} \mathrm{C}_{4}-\mathrm{M}_{98}$ & 2.018 & 2.024 & 2.039 \\
\hline
\end{tabular}

Table 2. Optimized bond lengths of Indacene structure in various $\mathrm{Bi}$ metallic complexes:

\begin{tabular}{|c|c|c|c|c|}
\hline Bond Length & ligand & Fe com & Ni com & Fe-Ni com \\
\hline $\mathrm{C}_{10}-\mathrm{C}_{6}$ & 1.358 & 1.441 & 1.463 & 1.438 \\
\hline $\mathrm{C}_{10}-\mathrm{C}_{9}$ & 1.469 & 1.465 & 1.473 & 1.454 \\
\hline $\mathrm{C}_{9}-\mathrm{C}_{8}$ & 1.425 & 1.467 & 1.448 & 1.453 \\
\hline $\mathrm{C}_{6}-\mathrm{C}_{7}$ & 1.522 & 1.431 & 1.463 & 1.443 \\
\hline $\mathrm{C}_{7}-\mathrm{C}_{8}$ & 1.510 & 1.463 & 1.474 & 1.451 \\
\hline $\mathrm{C}_{8}-\mathrm{C}_{25}$ & 1.396 & 1.405 & 1.401 & 1.440 \\
\hline $\mathrm{C}_{25}-\mathrm{C}_{14}$ & 1.403 & 1.406 & 1.402 & 1.372 \\
\hline $\mathrm{C}_{14}-\mathrm{C}_{13}$ & 1.425 & 1.467 & 1.448 & 1.479 \\
\hline $\mathrm{C}_{13}-\mathrm{C}_{26}$ & 1.396 & 1.404 & 1.401 & 1.370 \\
\hline $\mathrm{C}_{14}-\mathrm{C}_{15}$ & 1.463 & 1.464 & 1.473 & 1.478 \\
\hline $\mathrm{C}_{15}-\mathrm{C}_{16}$ & 1.366 & 1.431 & 1.462 & 1.465 \\
\hline $\mathrm{C}_{16}-\mathrm{C}_{17}$ & 1.518 & 1.441 & 1.463 & 1.463 \\
\hline $\mathrm{C}_{17}-\mathrm{C}_{13}$ & 1.510 & 1.466 & 1.474 & 1.481 \\
\hline $\mathrm{C}_{26}-\mathrm{C}_{9}$ & 1.403 & 1.405 & 1.402 & 1.433 \\
\hline $\mathrm{C}_{26}-\mathrm{C}_{53}(\mathrm{Me}$ substi $)$ & 1.491 & 1.490 & 1.494 & 1.492 \\
\hline $\mathrm{C}_{25}-\mathrm{C}_{49}(\mathrm{Me}$ substi) & 1.479 & 1.492 & 1.494 & 1.493 \\
\hline $\mathrm{C}_{6}-\mathrm{C}_{27}(\mathrm{Phe}$ substi) & 1.463 & 1.468 & 1.468 & 1.467 \\
\hline $\mathrm{C}_{16}-\mathrm{C}_{38}(\mathrm{Phe} \mathrm{substi})$ & 1.463 & 1.468 & 1.468 & 1.469 \\
\hline
\end{tabular}

Table 3. Optimized bond lengths of Cyclopentadienyl ligands in various bimetallic complexes:

\begin{tabular}{|c|c|c|c|}
\hline Bond Length & Fe com & Ni com & Fe-Ni com \\
\hline $\mathrm{C}_{18}-\mathrm{C}_{19}$ & 1.441 & 1.423 & 1.427 \\
\hline $\mathrm{C}_{19}-\mathrm{C}_{20}$ & 1.465 & 1.475 & 1.473 \\
\hline $\mathrm{C}_{20}-\mathrm{C}_{21}$ & 1.467 & 1.4448 & 1.4444 \\
\hline $\mathrm{C}_{21}-\mathrm{C}_{22}$ & 1.431 & 1.4447 & 1.4442 \\
\hline $\mathrm{C}_{22}-\mathrm{C}_{18}$ & 1.463 & 1.475 & 1.473 \\
\hline $\mathrm{C}_{1}-\mathrm{C}_{2}$ & 1.457 & 1.445 & 1.455 \\
\hline $\mathrm{C}_{2}-\mathrm{C}_{3}$ & 1.447 & 1.475 & 1.452 \\
\hline $\mathrm{C}_{3}-\mathrm{C}_{4}$ & 1.441 & 1.424 & 1.436 \\
\hline $\mathrm{C}_{4}-\mathrm{C}_{5}$ & 1.462 & 1.475 & 1.464 \\
\hline $\mathrm{C}_{1}-\mathrm{C}_{5}$ & 1.433 & 1.444 & 1.433 \\
\hline
\end{tabular}

\subsection{Electrostatic Potential Analysis}

Molecular electrostatic potential (ESP) is the most useful electrostatic property to Study the relation between structure and activity in a wide variety of chemical systems in both Electrophilic and Nucleophilic reactions. The negative ESP corresponds to nucleophilic sites (electron rich centers) shown as red shades on the ESP surface. Similarly, positive ESP corresponds to the electrophilic sites (electron deficient centers) shown in blue shades. The neutral sites are indicated by green shades. To predict the active sites for nucleophilic and electrophilic attack for the complexes, Potential increases in the order red $<$ orange $<$ yellow $<$ green $<$ blue. The electrostatic potential diagram of Complex is as shown in Fig. 3. 


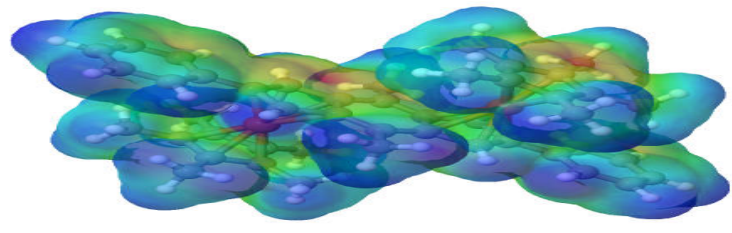

Figure 3. Molecular Electrostatic Potential surface of $(\mathrm{Cp} * \mathrm{Fe})_{2} \mathrm{Ic}$ '

\subsection{HOMO - LUMO Analysis}

The important concepts such as conjugation, aromaticity and lone pairs are well illustrated by frontier molecular orbitals. Frontier molecular orbital (FMO) energies decide whether the molecule is hard or soft. Ionization potential of the molecule is determined from the energy of the highest occupied molecular orbital (HOMO) and the electron affinity is calculates from the energy of lowest unoccupied molecular orbital (LUMO).

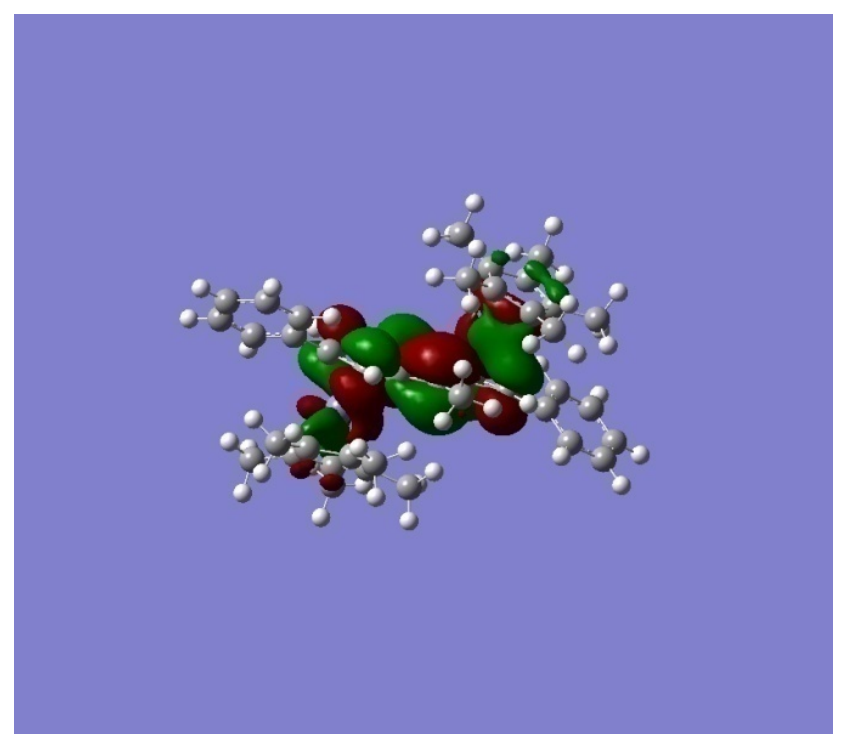

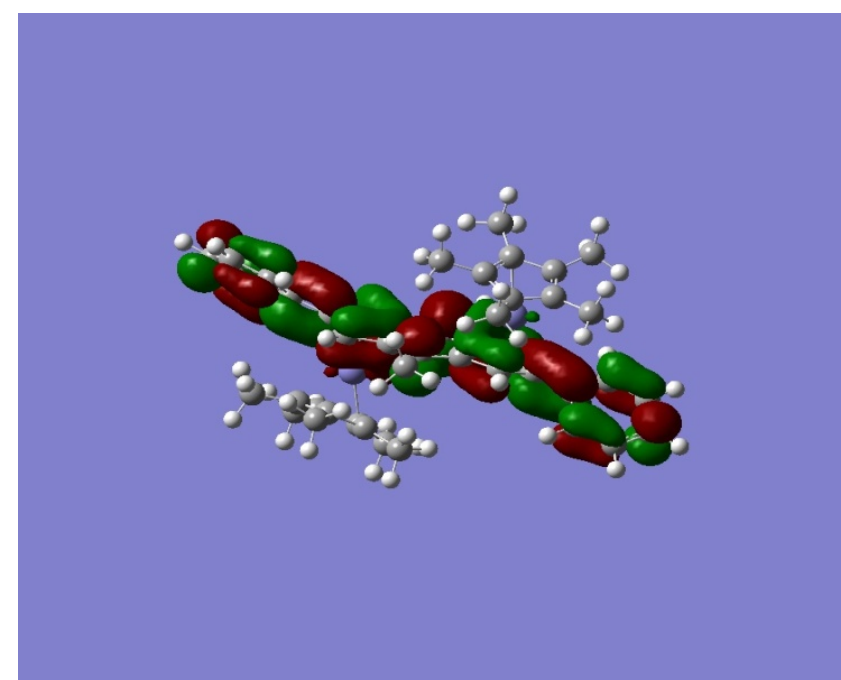

Figure 4(a). HOMO -125 and 4(b) LUMO-126 of (Cp*Fe) $)_{2}$ '

Energy difference between HOMO and LUMO orbitals is called as energy gap (DE) which determines the kinetic stability and chemical reactivity of a molecule. In case of Iron bimetallic complex, $\left(\mathrm{Cp}^{*} \mathrm{Fe}\right)_{2} \mathrm{Ic}$ ' the calculated HOMO - LUMO energy gap is $=0.25206 \mathrm{eV}$

This small HOMO-LUMO energy gap in an indication of capability of electronic transitions from occupied orbitals to unoccupied ones, the intramolecular electron transfer from HOMO to LUMO through $\pi$-conjugated path taking place within the molecule. When the energy gap between HOMO and LUMO is small, it enhances the reactivity by intramolecular charge transfer within the molecule [27].

In case of Nickel bimetallic complex, $\left(\mathrm{Cp}^{*} \mathrm{Ni}\right)_{2} \mathrm{Ic}$, the calculated energy gap is $=0.23852 \mathrm{eV}$, changes due to change in metal.

Where as in case of hetero bimetallic complexes, $(\mathrm{Cp} * \mathrm{Fe})$ Ic' $(\mathrm{Ni} \mathrm{Cp} *)$ the calculated energy gap is $=0.24365$

In case of a pure ligand 4, 8-dimethyl-2, 6-diphenyl-1, 5-dihydro-s-indacene the calculated energy gap between $\mathrm{HOMO}$ and LUMO is $0.267 \mathrm{eV}$.

Table 4. The total energy, dipole moment, frontier molecular orbital energies and charge of ligand and bimetallic complexes

\begin{tabular}{|c|c|c|c|c|}
\hline Property & Ligand & $(\mathrm{Cp} * \mathrm{Fe})_{2} \mathrm{Ic}$ & $\left(\mathrm{Cp} \mathrm{c}^{\prime} \mathrm{Ni}\right)_{2} \mathrm{Ic} \mathrm{c}^{\prime}$ & $\left(\mathrm{Cp}^{*} \mathrm{Fe}\right) \mathrm{Ic}^{\prime}\left(\mathrm{Ni} \mathrm{Cp}{ }^{*}\right)$ \\
\hline HOMO(eV) & -0.29691 & -0.25293 & -0.23424 & -0.24666 \\
\hline LUMO(eV) & -0.01713 & 0.00087 & -0.00428 & 0.00301 \\
\hline Energy gap $\Delta \mathrm{E}(\mathrm{eV})$ & 0.27978 & 0.25206 & 0.23852 & 0.10947398 \\
\hline Total energy(a.u) & 0.13252862 & 0.10058381 & 0.12620178 & 1.7805 \\
\hline Dipole moment(Debye) & 0.0640 & 1.0296 & 0.1213 & 98 \\
\hline No of atoms & 48 & 98 & 98 & 380 \\
\hline No of electrons & 178 & 378 & 382 & 0 \\
\hline Charge & 0 & 0 & 0 & singlet \\
\hline Spin & singlet & singlet & singlet & \\
\hline
\end{tabular}




\subsection{Normal Mode Analysis}

The vibrational analysis of ligand and their bimetallic complexes is carried out in Gaussian software using semi empirical methods with parametric methods (PM6).The vibrational frequencies of bimetallic complexes were calculated in different oxidation states to predict the existence of mixed valence complexes.

The IR spectra of ligand and bi metallic complexes were calculated in the wave number range of $400-3500 \mathrm{~cm}^{-1}$. Firstly the IR spectrum of ligand 4 ,

8-dimethyl-2,6-diphenyl-1,5-dihydro-s-indacene is predicted using method Restricted PM6 with ZDO basis set to observe the vibrational frequencies of ligand in absence of
Metal. Later using same method vibrational frequencies and intensities of bimetallic complexes were calculated to predict the effect of metal atoms in characteristic stretching and bending frequencies of substituents.

The IR spectra of ligand and their bimetallic complexes show the characteristic stretching and bending vibrational frequencies of methyl groups and aromatic rings. Most of vibrational bands are combined with the other vibrational ones.

The calculated IR spectrums of ligand and studied bimetallic complexes are given below from figure $5 \mathrm{a}$ to figure $5 \mathrm{~g}$.

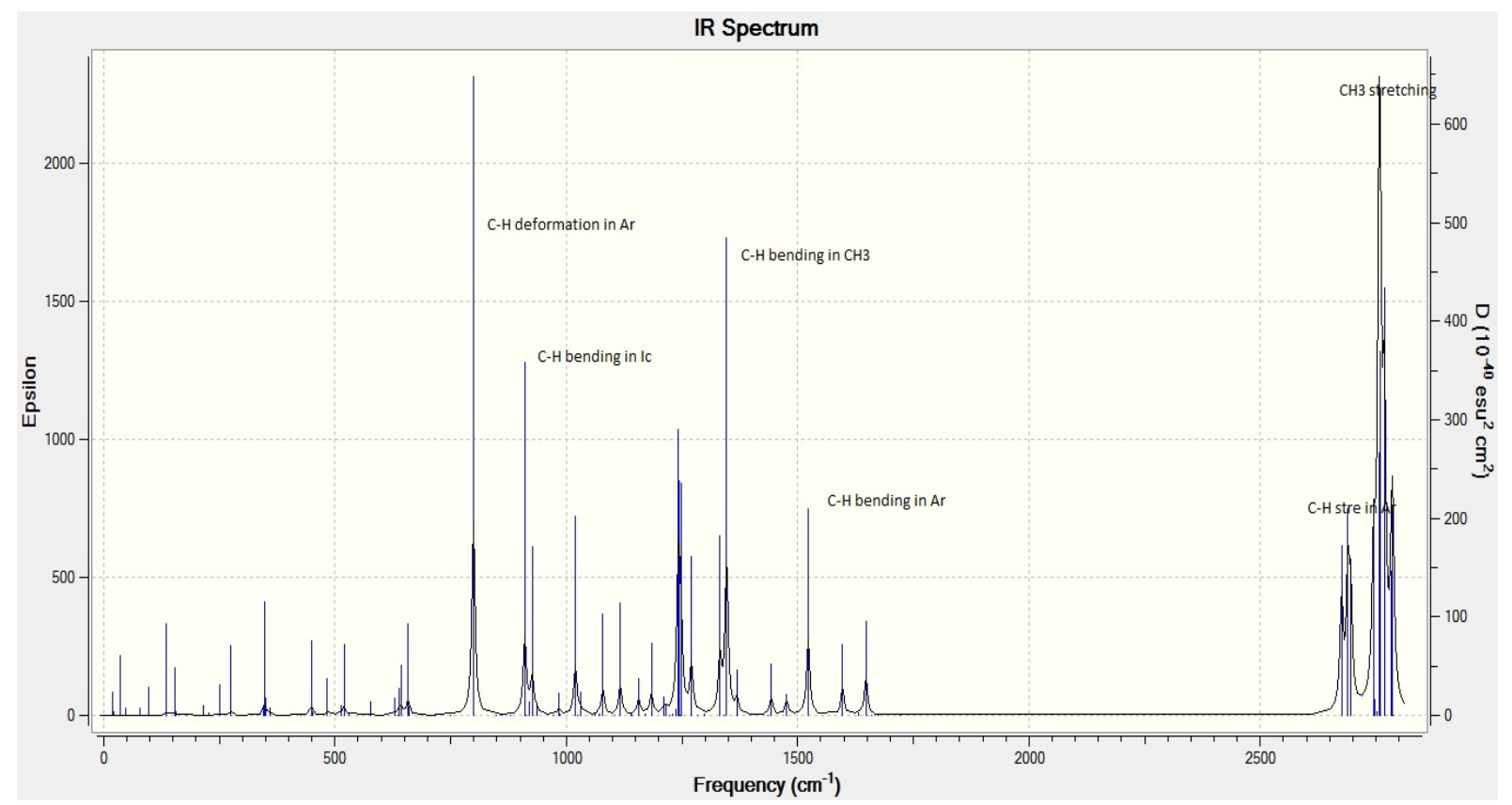

Figure 5a. IR spectra of ligand 4, 8-dimethyl-2, 6-diphenyl-1, 5-dihydro-s-indacene

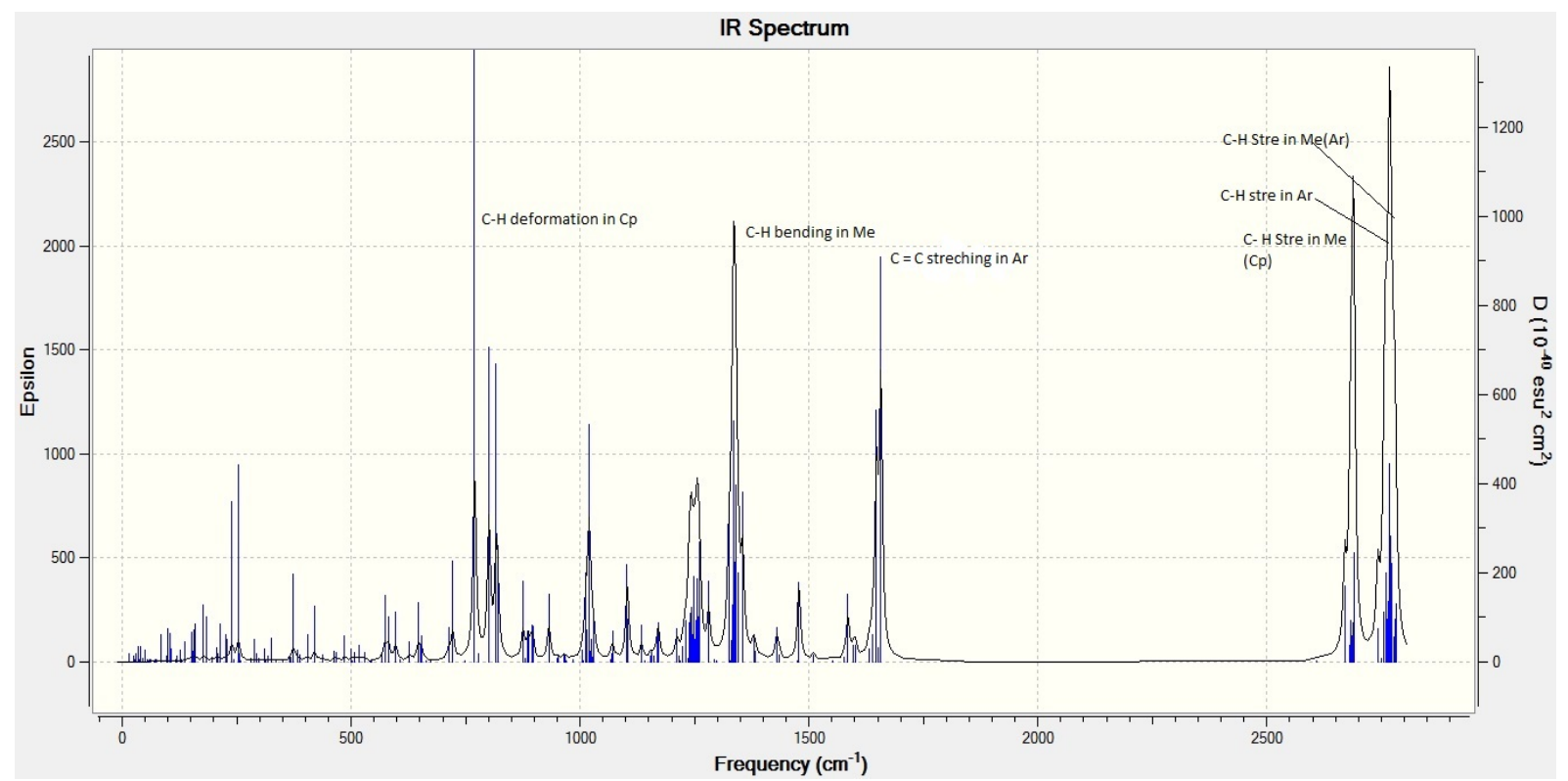

Figure 5b. IR spectrum of $\left(\mathrm{Cp}^{*} \mathrm{Fe}\right)_{2} \mathrm{Ic}^{\prime}$ in neutral state 


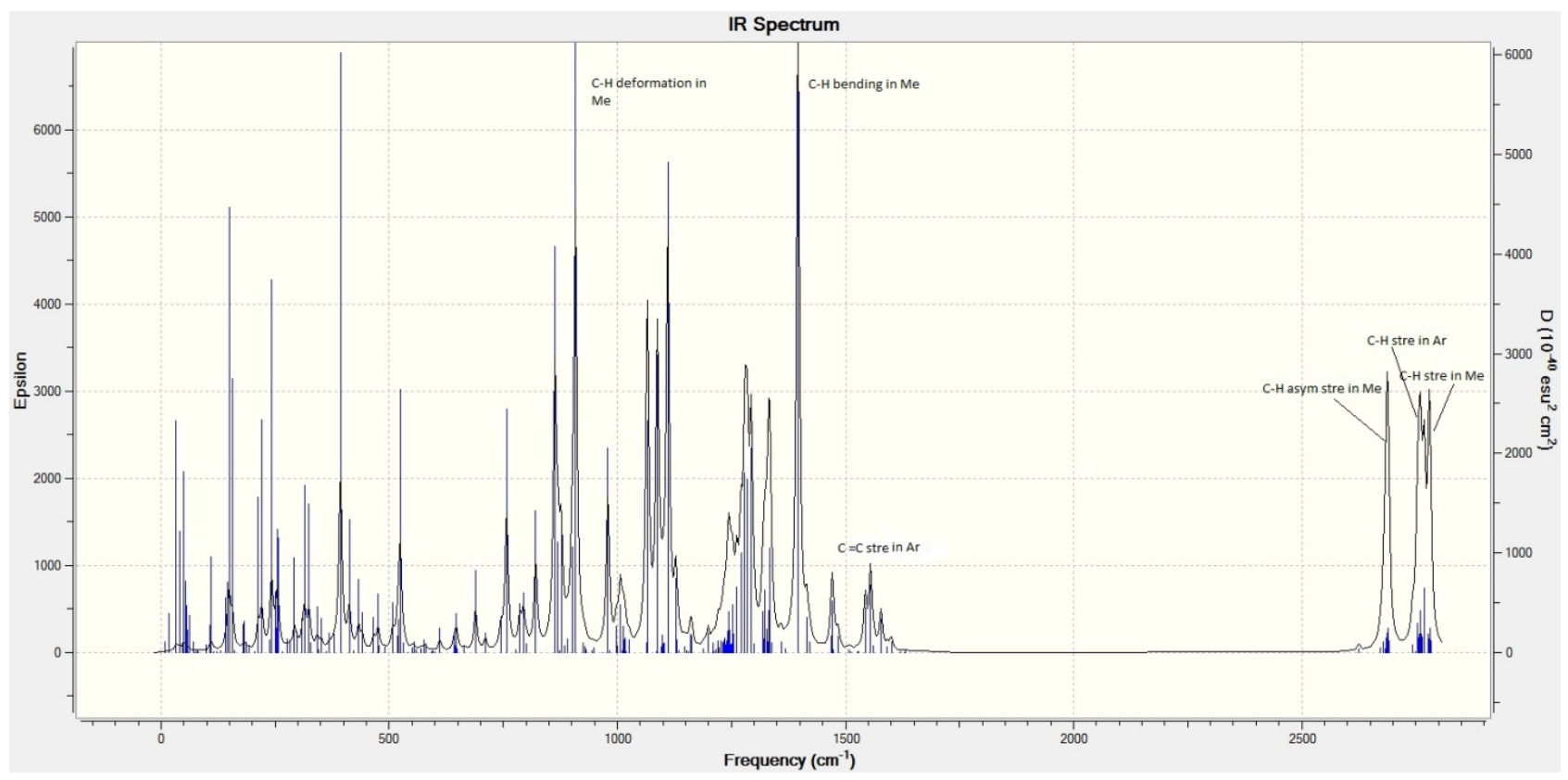

Figure 5c. IR spectrum of $\left(\mathrm{Cp}^{*} \mathrm{Fe}\right)_{2} \mathrm{Ic}$ ' in +1 oxidation state

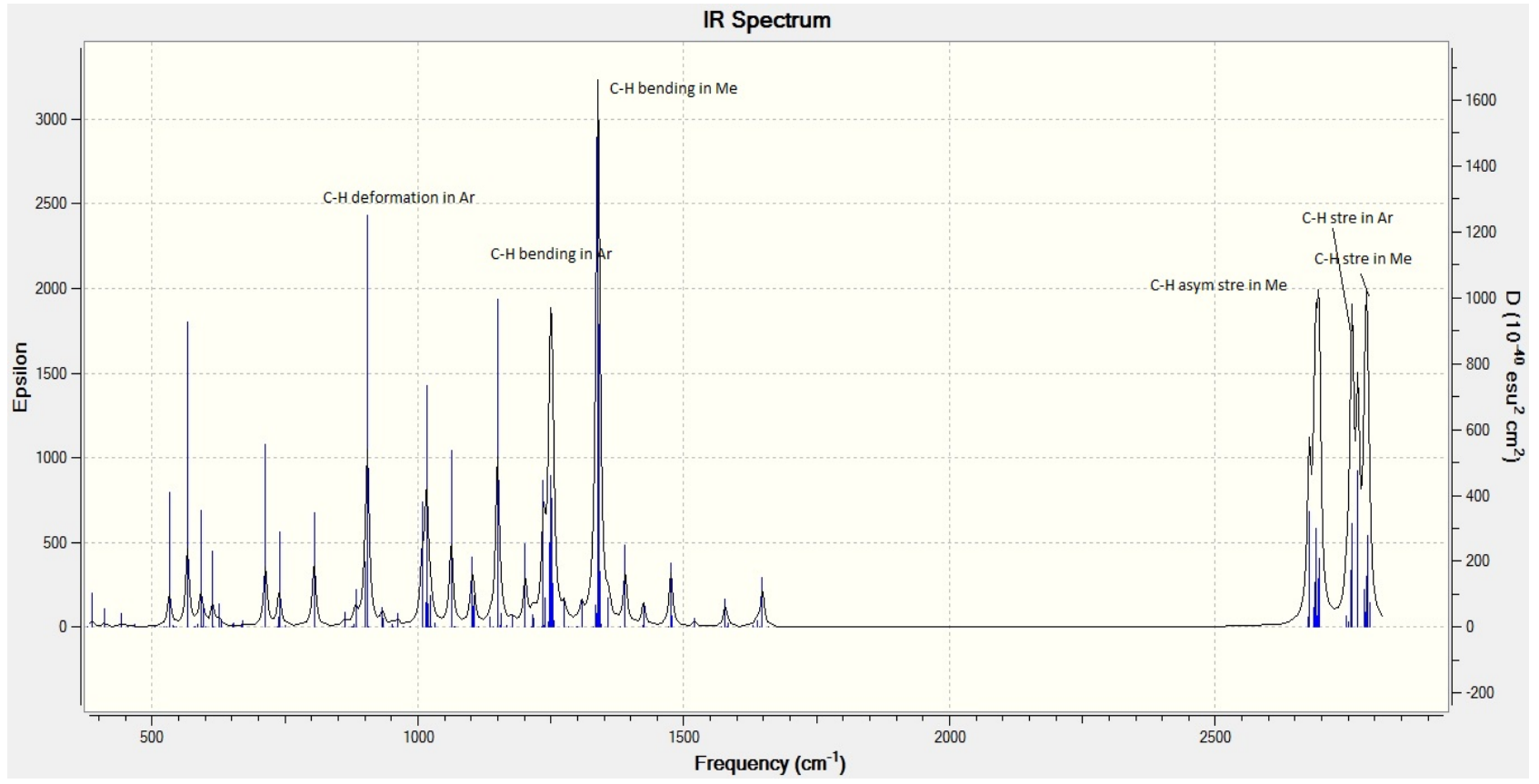

Figure 5d. IR spectrum of $\left(\mathrm{Cp}^{*} \mathrm{Ni}\right)_{2} \mathrm{Ic}$ ' in neutral state 


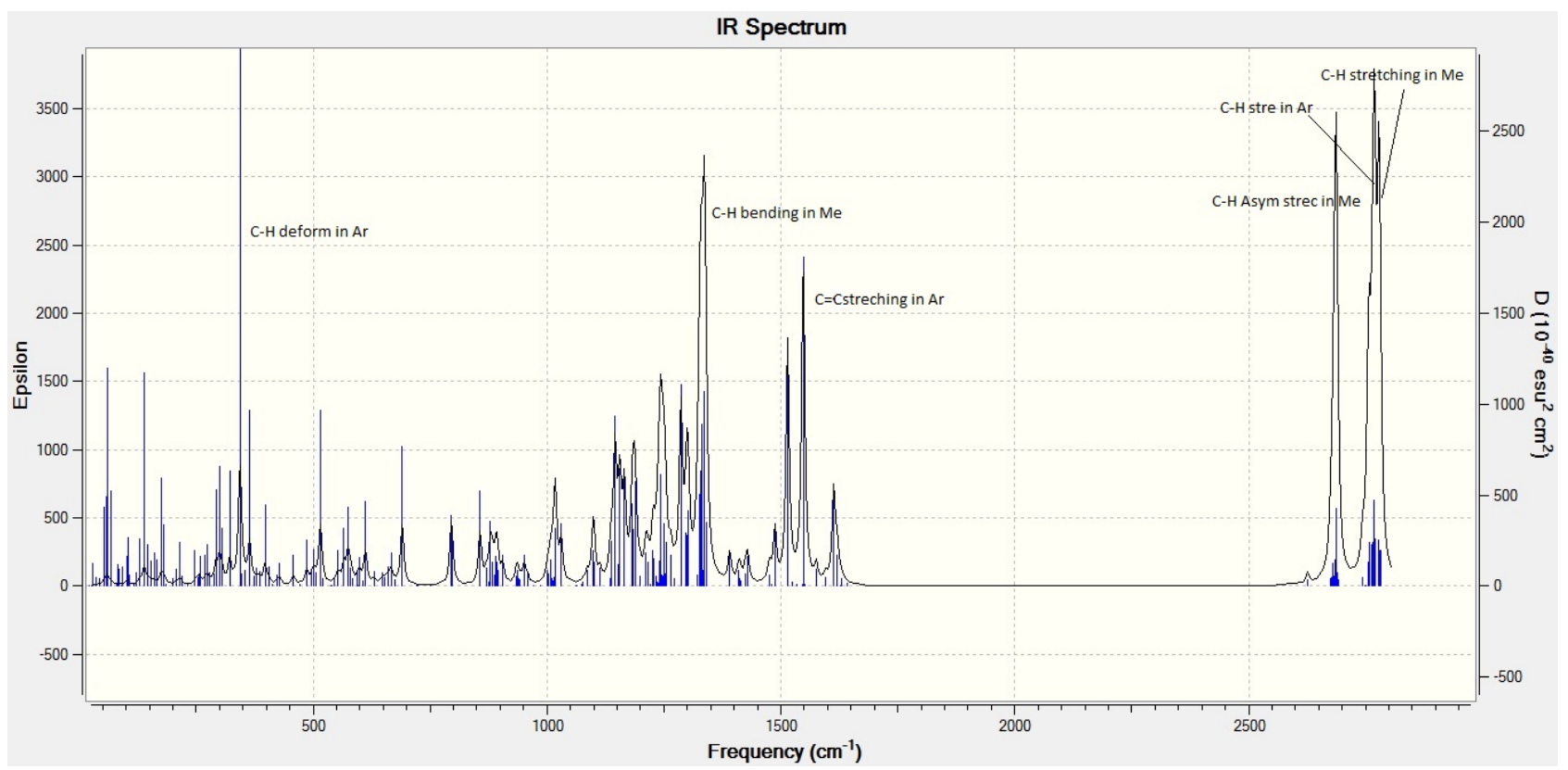

Figure 5e. IR spectrum of $\left(\mathrm{Cp}^{*} \mathrm{Ni}\right)_{2} \mathrm{Ic}$ ' in +1 oxidation state

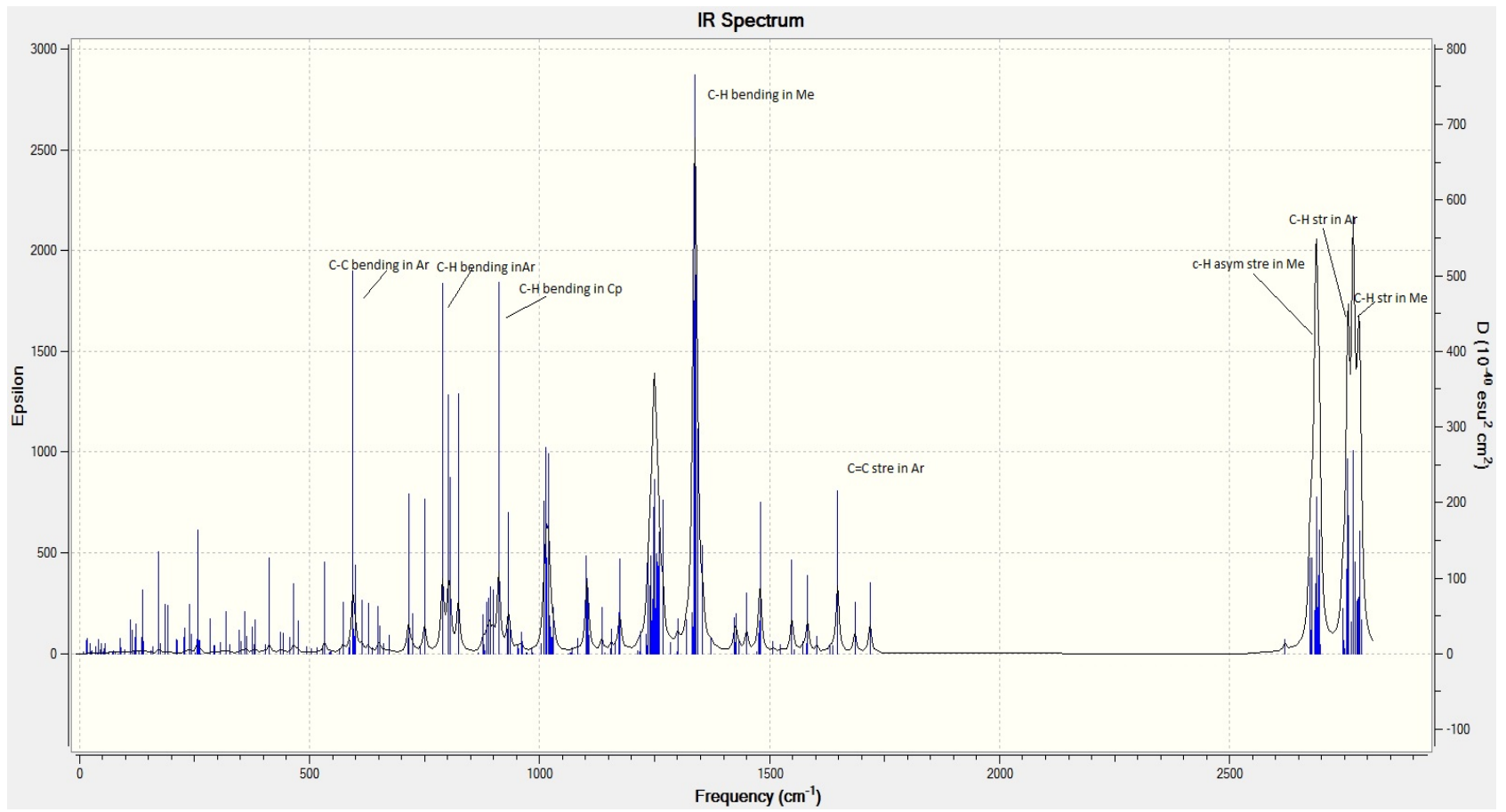

Figure 5f. IR spectrum of ( $\left.\mathrm{Cp}^{*} \mathrm{Fe}\right) \mathrm{Ic}^{\prime}\left(\mathrm{NiCp}^{*}\right)$ in neutral state 


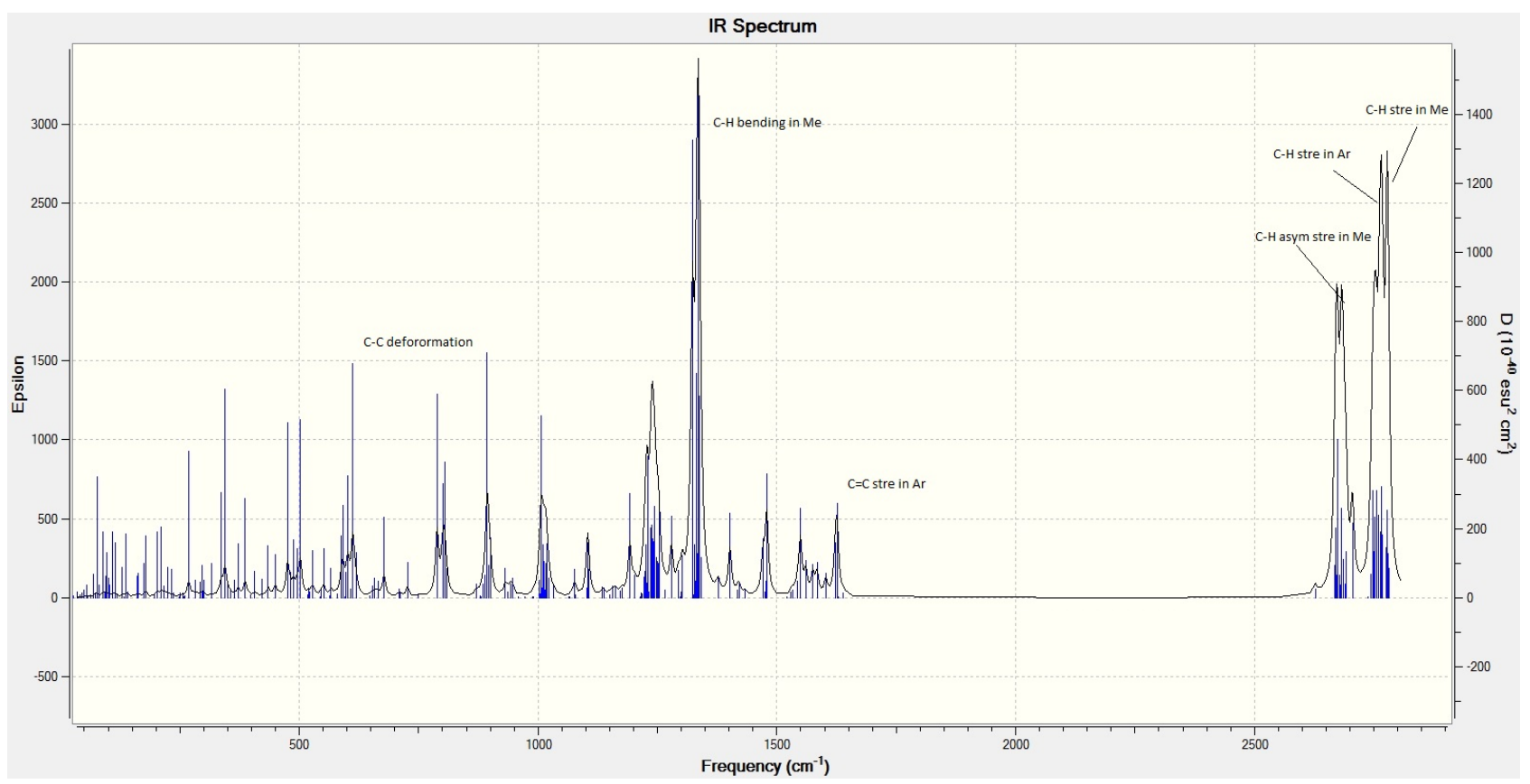

Figure 5g. IR spectrum of $\left(\mathrm{Cp}^{*} \mathrm{Fe}\right) \mathrm{Ic}^{\prime}(\mathrm{Cp} * \mathrm{Ni})$ in +1 oxidation state

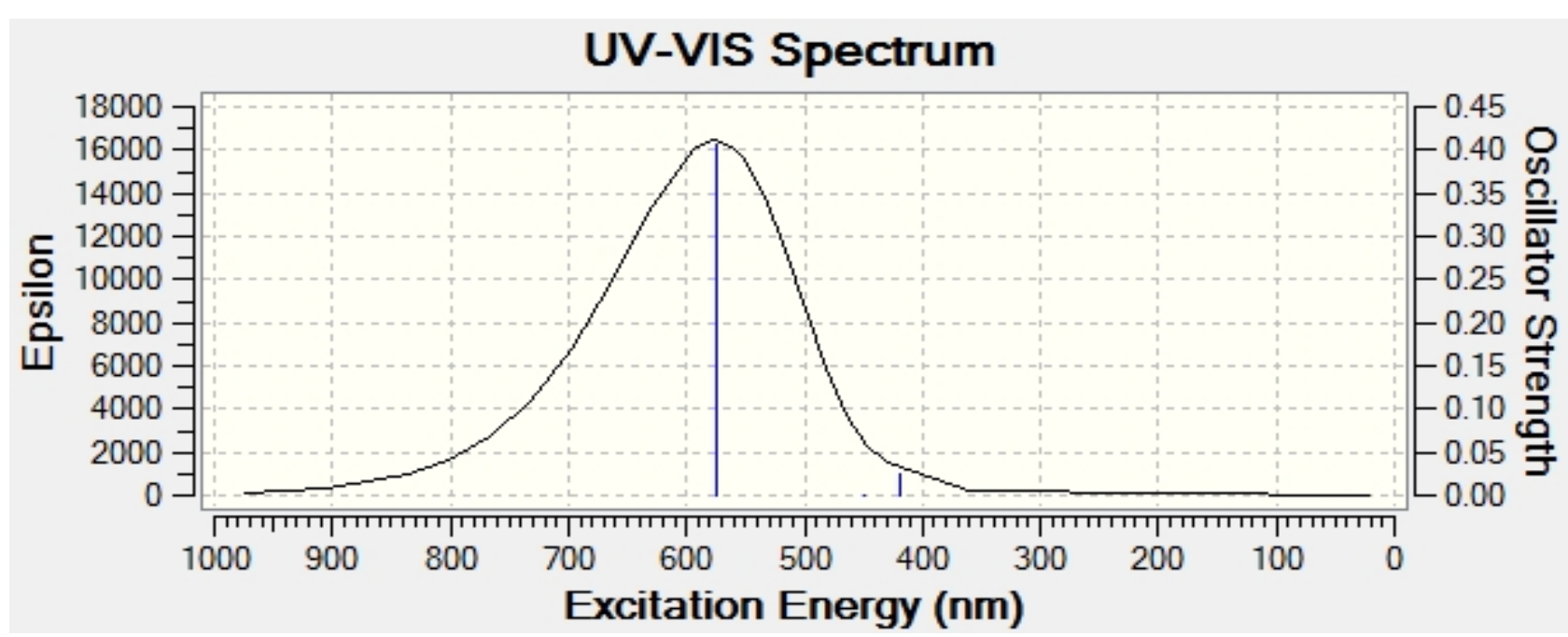

Figure 6a. UV spectra of Ligand 4, 8-dimethyl-2, 6-diphenyl-1, 5-dihydro-s-indacene

\section{Spectrum}

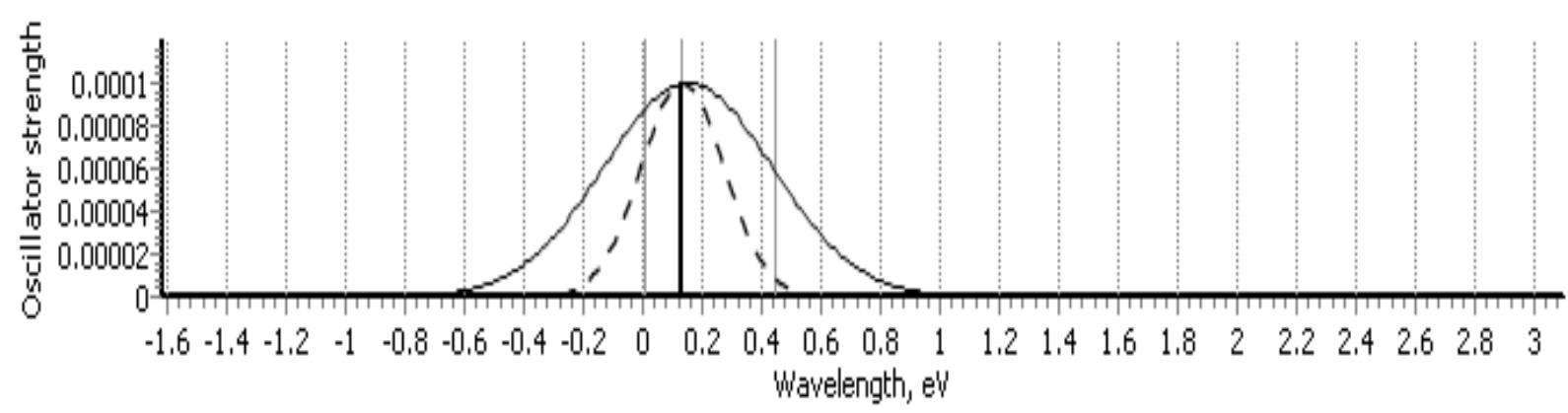

Figure 6b. UV-VIS-NIR spectrum of $\left(\mathrm{Cp}^{*} \mathrm{Fe}\right)_{2} \mathrm{Ic}^{\prime}$ 


\subsection{UV-Vis Spectral Analysis}

Semi empirical methods whose primary aim is to calculate excited states and hence to predict electronic spectra [24]-[26].In the theoretical investigation to predict UV spectra, analysis of single point energy calculations are carried out at semi empirical level using TD SCF method for ligand and Bimetallic complexes.

For ligand uv-visible spectrum has been recorded in region of 200-1000 $\mathrm{nm}$ and calculated absorptions at maximum is $=575.44 \mathrm{~nm}$ and Oscillator strength $=0.4058$ as shown in figure (6a).

Quantum chemical computations were continued to investigate the electronic properties of above stated homo and hetero bimetallic complexes.

Fe complex , $\left(\mathrm{Cp}^{*} \mathrm{Fe}\right)_{2} \mathrm{Ic}$ ' in neutral state exhibit the absorption maxima at $0.2047 \mathrm{eV}$ indicated by thick line and for its ionic complex in +1 oxidation state exhibit the absorption maxima at $0.1345 \mathrm{eV}$ indicated by dotted line in the UV -VIS-NIR spectra as shown in figure $6 \mathrm{~b}$.

In the same manner theoretical absorption bands are calculated for $\left(\mathrm{Cp}^{*} \mathrm{Ni}\right)_{2} \mathrm{Ic} c^{\prime},(\mathrm{Cp} * \mathrm{Fe}) \mathrm{Ic}^{\prime}\left(\mathrm{NiCp}^{*}\right)$ as well as their ionic complexes with +1 oxidation state.

$\mathrm{Ni}$ complex $\left(\mathrm{Cp}^{*} \mathrm{Ni}\right)_{2} \mathrm{Ic}$ ' in neutral state exhibit absorption maxima at $1.535 \mathrm{eV}$ indicated by thick line and for its ionic complex with +1 oxidation state absorption maxima at $0.9079 \mathrm{eV}$ indicated by dotted line in UV -VIS-NIR spectra as shown in below figure (6c)

In case of hetero bimetallic complex $\left(\mathrm{Cp}^{*} \mathrm{Fe}\right) \mathrm{Ic}^{\prime}\left(\mathrm{NiCp}^{*}\right)$ in neutral state exhibit absorption maxima at $0.21079 \mathrm{eV}$ indicated by thick line and for its ionic complex with +1 oxidation state absorption maxima at $0.62858 \mathrm{ev}$ indicated by dotted line in UV -VIS-NIR spectra as shown in below figure $(6 \mathrm{~d})$

\section{Conclusions}

The studied bimetallic complexes in this paper are found to be stable confirmed by UV- Vis spectral analysis. The geometric parameters and vibrational frequencies, electronic absorption maximum wavelengths and HOMO-LUMO energy gap of above stated homo and hetero bimetallic complexes have been calculated at semi empirical methods with PM6 in ground state. In these complexes due to delocalisation of pi electrons over the whole molecule, the intra valence charge transfer band was observed in the UV-NIR region. It is indicated that there is less energy gap between the bonding and anti-bonding molecular orbitals.

\section{Spectrum}

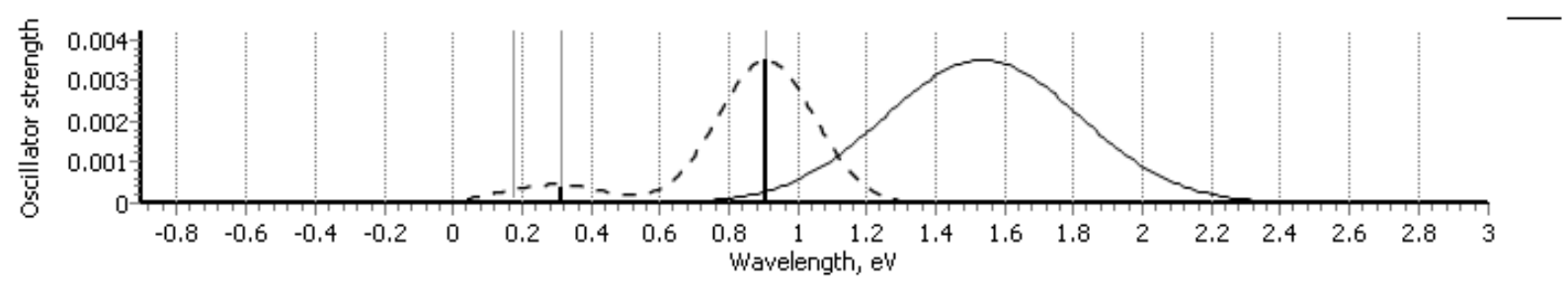

Figure 6c. UV-VIS-NIR spectrum of $\left(\mathrm{Cp}^{*} \mathrm{Ni}\right)_{2} \mathrm{Ic}{ }^{\prime}$

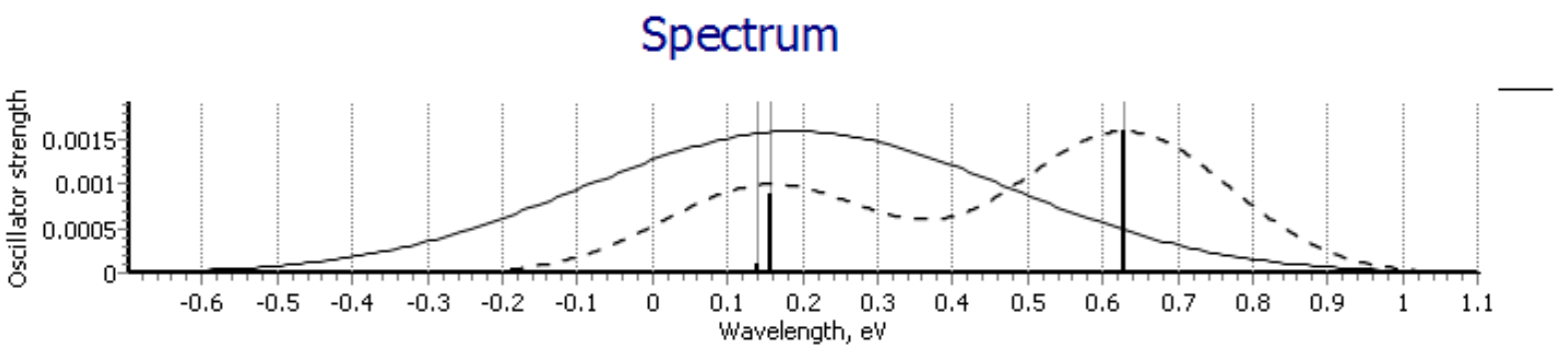

Figure 6d. UV-VIS-NIR spectrum of (Cp*Fe) Ic' $\left(\mathrm{NiCp}^{*}\right)$ 


\section{REFERENCES}

[1] (a) S. Barlow and D. O'Hare, Chem. Rev., 1997, 97, 637; (b) A. Ceccon, S. Santi, L. Orian and A. Bisello, Coord. Chem. Rev., 2004, 248, 683; (c) P. Aguirre-Etcheverry and D. O'Hare, Chem. Rev., 2010, 110, 4839.

[2] 2 W. L. Bell, C. J. Curtis, A. Miedaner, C. W. Eigenbrot Jr, R. C. Haltiwanger, C. G. Pierpont and J. C. Smart, Organometallics, 1988, 7, 691.

[3] J. M. Manriquez, M. D. Ward, W. M. Reiff, J. C. Calabrese, N. L. Jones, P. J. Carroll, E. E. Bunel and J. S. Miller, J. Am. Chem. Soc., 1995, 117, 6182.

[4] W. L. Bell, C. J. Curtis, C. W. Eigenbrot Jr, C. G. Pierpont, J. L. Robbins and J. C. Smart, Organometallics, 1987, 6, 266.

[5] M. Sato, M. Suzuki, M. Okoshi, M. Kurasina and M. Watanabe, J. Organomet. Chem., 2002, 648, 72.

[6] P. Roussel, M. J. Drewitt, D. R. Cary, C. G. Webster and D. O'Hare, Chem. Commun., 1998, 2205.

[7] D. R. Cary, C. G. Webster, M. J. Drewitt, S. Barlow, J. C. Green and D. O'Hare, Chem. Commun., 1997, 953.

[8] P. Roussel, D. R. Cary, S. Barlow, J. C. Green, F. Varret and D. O'Hare, Organometallics, 2000, 19, 1071.

[9] M. T. Garland, J.-Y. Saillard, I. Cha'vez, B. Oe"lckers and J. M. Manri'quez, THEOCHEM, 1997, 390, 199-208.

[10] (a) D. MacLeod Carey, C. Morales-Verdejo, A. Munoz-Castro, F. Burgos, D. Abril, C. Adams, E. Molins, O. Cador, I. Chavez, J. M. Manriquez, R. Arratia-Perez and J.-Y. Saillard, Polyhedron, 2010, 29, 1137; (b) A. Munoz-Castro, D. MacLeod Carey, C. Morales-Verdejo, I. Chavez, J. M. Manriquez and R. ArratiaPerez, Inorg. Chem., 2010, 49, 4175.

[11] L. Orian, P. Ganis, S. Santi and A. Ceccon, J. Organomet. Chem., 2005, 690, 482. 14 S. Santi, L. Orian, C. Durante, E. Z. Bencze, A. Bisello, A. Donoli, A. Ceccon, F. Benetollo and L. Crociani, Chem.-Eur. J., 2007, 13, 7933.

[12] E. Hückel, Zeitschrift für Physik, 70, 204, (1931); 72, 310, (1931); 76, 628 (1932); 83, 632, (1933)

[13] Hückel Theory for Organic Chemists, C. A. Coulson, B. O'Leary and R. B. Mallion, Academic Press, 1978.

[14] Andrew Streitwieser, Molecular Orbital Theory for Organic
Chemists, Wiley, New York, (1961)

[15] R. Hoffmann, Journal of Chemical Physics, 39, 1397, (1963)

[16] R. Pariser and R. Parr, Journal of Chemical Physics, 21, 466, 767, (1953)

[17] C. J. Cramer, Essentials of Computational Chemistry, Wiley, Chichester, (2002), pg 126-131

[18] J. J. P. Stewart, Reviews in Computational Chemistry, Volume 1, Eds. K. B. Lipkowitz and D. B. Boyd, VCH, New York, 45, (1990)

[19] Michael J. S. Dewar \& Walter Thiel (1977). "Ground states of molecules. 38. The MNDO method. Approximations and parameters". Journal of the American Chemical Society. ACS Publications. 99 (15): 4899-4907. Doi: 10.1021/ja00457a004.

[20] James J. P. Stewart (1989). "Optimization of parameters for semi empirical methods I. Method". The Journal of Computational Chemistry. Wiley InterScience. 10 (2): 209220. Doi: $10.1002 /$ jcc.540100208.

[21] Gerd B. Rocha; Ricardo O. Freire; Alfredo M. Simas; James J. P. Stewart (2006). "RM1: A reparameterization of AM1 for $\mathrm{H}$, C, N, O, P, S, F, C, Br, and I". The Journal of Computational Chemistry. Wiley InterScience. 27 (10): 1101-1111. PMID 16691568. Doi:10.1002/jcc.20425.

[22] James J. P. Stewart (2007). "Optimization of Parameters for Semi empirical Methods V: Modification of NDDO Approximations and Application to 70 Elements". The Journal of Molecular Modeling. Springer. 13 (12): 1173-1213. Doi: 10.1007/s00894-007-0233-4.

[23] M. Zerner, Reviews in Computational Chemistry, Volume 2, Eds. K. B. Lipkowitz and D. B. Boyd, VCH, New York, 313, (1991)

[24] M. B. Robin and P. Day, Adv. Inorg. Chem. Radiochem., 1967, $10,24$.

[25] 18 T. A. Albright, J. K. Burdett and M. H. Whangbo, Orbital Interactions in Chemistry, John Wiley and Sons, New York, 1985

[26] Nanda, D. N. and Jug, K., Theoretica Chimica Acta, 57, 95, (1980)

[27] A.N. Titov, Yu. M. Yarmoshenko, P. Bazylewski, M.V. Yablonskikh, E.Z. Kurmaev, R. Wilks, , V.A. Tsurin, A. Moewes, V.V. Fedorenko, O.N. Suvorova, S. Yu. Ketkov, M. Neumann, G.S. Chang. Chemical Physics Letters 497 (2010) 187-190. 